\title{
Osteopetro-Rickets: A Rare Paradoxical Association in an Infant
}

\author{
Patil MB' \\ 'Dr. Mandar Bhausaheb Patil, MBBS, DCH, DNB (Paediatrics), Department of Paediatrics, Dr. D. Y. Patil Medical College and \\ University, Kolhapur, Maharashtra, India.
}

Address for correspondence: Dr. Mandar B. Patil, Email: rmandarpatil@hotmail.com

\begin{abstract}
Infantile malignant osteopetrosis is a hereditary bone disease with intense positive balance of body calcium. Osteopetro-rickets is a very rare paradoxical association of infantile osteopetrosis and rickets. This is a case report of an infant with osteopetro- rickets. He presented with severe anaemia, splenomegaly, hepatomegaly and clinical signs of rickets. The clinical, biochemical and skeletal survey showed osteopetrosis and rickets. We also describe the pathophysiologic mechanism and various management options.
\end{abstract}

Key words: Osteopetrosis, Osteopetro- rickets, Rickets

Abbreviations: - BMT - bone marrow transplantation, Ca- calcium, P-phosphorus

\section{Introduction}

A German radiologist, Albers- Schonberg first described osteopetrosis in 1904'. Infantile malignant osteopetrosis is a hereditary bone disease with intense positive balance of body calcium ${ }^{2}$. Rickets associated with osteopetrosis is called osteopetro- rickets. The presence of rickets in a setting of intense positive body calcium, in osteopetrosis is paradoxical. This case reports osteopetro- rickets in an infant, reviews the very sparse literature that is available so far and briefly outlines the understanding of this disorder and its management.

\section{The Case}

Six months old boy, born of a consanguineous marriage, was brought with failure to thrive, poor feeding, pallor, lethargy and irritability, and abdominal distension. The clinical examination was suggestive of florid rickets (frontal bossing, wide anterior fontanel, rachitic rosary, and widening at wrists and ankles), severe pallor, gross splenomegaly (spleen was palpable $8 \mathrm{~cm}$ below the left costal margin) and mild hepatomegaly. His growth parameters were falling below the fifth percentile on growth charts. His investigations revealed Hemoglobin $7.2 \mathrm{gm} \%$ and thrombocytopenia $\left(1,03,000 / \mathrm{mm}^{3}\right)$. The ultrasonography scan revealed severe splenomegaly and mild hepatomegaly. The skeletal survey demonstrated diffuse bony sclerosis and bone in bone appearance suggestive of osteopetrosis and significant metaphyseal cupping and fraying of lower end of femurs (Figure 1). The serum calcium was $7.5 \mathrm{mg} / \mathrm{dl}$, serum phosphorus 2.5 $\mathrm{mg} / \mathrm{dl}$ and alkaline phosphatase $1600 \mathrm{U} / \mathrm{L}$ and serum Ca xP product was less than 20. The 1,25-dihydroxy vitamin D3 level was undetectable and serum parathyroid hormone was elevated $(800 \mathrm{pg} / \mathrm{ml})$. Thus, the clinical examination, blood investigations and skeletal survey showed osteopetrosis with rickets. He was treated with high dose vitamin D3 and oral calcium supplements with high calcium and phosphorus diet.

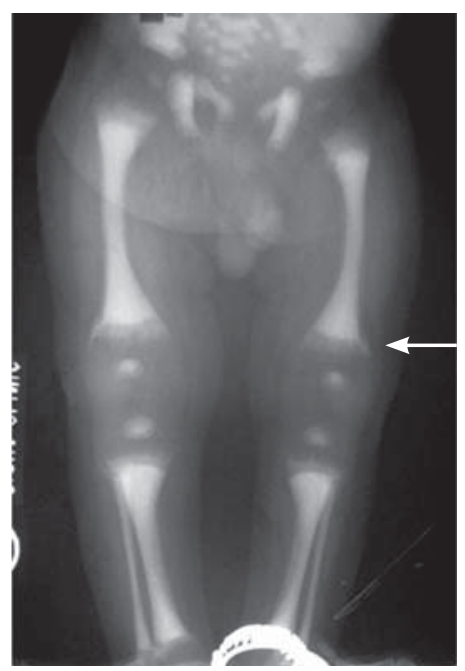

Fig 1: Demonstrating bone in bone appearance of all bones and cupping and fraying of the metaphysis of femora. 


\section{Discussion}

This case, clearly had, clinical and radiological features of osteopetrosis. What was striking was clinical, biochemical and radiological evidence of rickets in addition to osteopetrosis.

Osteopetro- rickets is a rare paradoxical complication of infantile osteopetrosis ${ }^{2,3,4}$. It results from the inability of the osteoclasts to maintain normal calcium (Ca) and Phosphorus (P) balance in the extracellular fluid $^{2}$. In osteopetrosis, there is excess calcium reserve and hypophosphatemia, but when it is complicated by rickets there is insufficient $\mathrm{Ca} \times \mathrm{P}$ product to mineralize the growing bone ${ }^{5}$. In coexistent osteopetrosis and rickets, $99 \%$ of the calcium is shut off in the bone and is not available as a source of these minerals and the $\mathrm{Ca}$ $x \mathrm{P}$ product will become less than 40 , thus insufficient for mineralisation, as in this case. In such cases, there is a chance for hypocalcemic tetany ${ }^{5}$. Persistence of hypocalcemia and hypophosphatemia results in inability to mineralize newly formed chondroid and osteoid and the paradoxical association of rickets and osteopetrosis. Low calcium and high phosphate diet prescribed in osteopetrosis may further decrease the availability of calcium; hence in rickets liberal calcium is required. Low dose steroid therapy, which is found effective in treating and preventing the haematological problems in osteopetrosis may blunt the intestinal response to maximal vitamin $D$ stimulation as well ${ }^{2}$. The general view is to treat rickets in this co- morbid situation as it will improve well being, decrease irritability and decrease recurrent respiratory tract infections. This may also help in preparing the patient for future bone marrow transplantation.

Treatment options include liberal $\mathrm{Ca}$ and $\mathrm{P}$ diet with extra Ca carbonate supplement and vitamin D3 2,3,4. BMT is the only effective treatment for osteopetrosis. It provides hematopoietic stimulus that can differentiate into normal osteoclasts ${ }^{6,7}$. Prognosis is uniformly poor in absence of BMT; most of the children succumb to the disease by early childhood due to anaemia, bleeding and infections. Current opinion regarding the clinical treatment of patients with osteopetro- rickets involves first, the resolution of the rickets, followed by BMT to resolve the osteopetrosis. Though, there are case reports of successful BMT in osteopetrosis, at present no case of osteopetro- rickets successfully treated with BMT has been described in literature.

\section{References}

1. Albers-Schonberg $\mathrm{H}$ (1904) Roentgen bilder einer seltenen Kochennerkrankung Munch Med Wochenschr 51:365 (cross reference)

2. Kaplan FS, August CS, Fallon MD, Gannon F, Haddad $\mathrm{JH}$. Osteopetrorickets: The paradox of plenty. Pathophysiology and treatment. Clin Orthop Relat Res 1993;294:64-78

3. Datta V, Prajapati NC, Kamble M, Pathak S. Osteopetrorickets. Indian Pediatr 2000; 37:98-9.

4. Oliveira G, Boechat MI, Amaral SM, Young LW. Osteopetrosis and rickets: An intriguing association. Am J Dis Child 1986;40:377-78.

5. McCaryLC,SmithCM,DeLucaHF.Hypophosphatemia and the development of rickets in osteopetrotic (OP/ OP) mice. J Bone Miner Res 1997;12:1944-51.

6. Gerritsen EJ, Vossen JM, Fasth A, Friedrich W, Morgan G, Padmos A, et al. Bone marrow transplantation for autosomal recessive osteopetrosis. A report from the working party on In Born Errors of the European Bone Marrow Transplantation Group. J Pediatr 1994;125:896-902

7. Fasth A, Porras O. Human malignant osteopetrosis: pathophysiology, management and the role of bone marrow transplantation. Pediatr Transplant 1999;3 Suppl 1: 102-7.

\section{How to cite this article?}

Patil MB. Osteopetro-Rickets: A Rare Paradoxical Association in an Infant. J Nepal Paediatr Soc 2012;32(1):88-89. 